\title{
7. Policy Disasters Waiting to Happen: When predictable disasters flow from government decisions
}

\author{
Peter Mumford
}

I must confess that on reflection I did wonder whether, as a practising New Zealand public servant, it was a career-limiting move to accept an invitation to make a presentation on government decisions as the cause of policy failure. Being a public policy advisor, I probably contributed to a number of suboptimum regulatory regimes - those that have failed to deliver as expected. So perhaps reviewing these failures is a case of me looking in the mirror and seeing who is actually looking back. For public servants it is an occupational hazard: you can be associated sometimes with the success, but also sometimes with the failure, of the policies you have been working on and promoting.

The policy issue I have chosen to analyse concerns the challenge of creating resilient regulatory regimes. My study is informed by a recent case of regulatory failure in New Zealand resulting in the so-called 'leaky building crisis', but also work that Treasury has undertaken on best regulatory practice. The insights presented of regulatory failure resulting in the leaky building crisis were informed by my own research in this area, which has now been published by the Institute of Policy Studies (Mumford 2011).

\section{Two Lenses: The human face and the policy opportunity}

I would like to make clear from the outset that for many affected people, New Zealand's leaky building crisis is intensely personal. Their stories - which we read in the newspapers quite often - illustrate how people's lives can be affected when the state gets it wrong. If your units of analysis are individuals, families and communities, events like the leaky building crisis have a significant and dramatic effect, and we need to acknowledge that. For most of us in the public policy world, however, failures present a challenge: what went wrong? Why did it happen; and how can we ensure it never happens again? How can we learn from the mistakes of the past to create a better future? That is the public policy challenge that many of us face today. 


\section{The Broader Problem}

Turning to the regulatory failure that led to the leaky building crisis, I know there will be differences of opinion regarding the villain in the piece. Some will put the crisis down to poor workmanship on the job, and some people clearly attribute it to poor-quality builders more generally. Others will argue that it arose because the state retreated from its core function of keeping people safe, relying instead on market disciplines. Both factors are probably relevant. In my view, however, the leaky building crisis was first and foremost a failure of performance-based regulation as it was implemented in New Zealand. By studying the leaky building crisis, we can certainly learn something about building regulation, but more importantly we can learn a lot about this novel regulatory approach that promised so much but ultimately did not live up to expectations.

Essentially, the leaky building crisis was a symptom of a broader problem. This problem (and its solution) can be found in the goal-based, non-prescriptive regulatory approaches that were adopted in the 1980s and 1990s in the building industry, the occupational health and safety area, and in environmental management. Many of these same regulatory approaches continue to be promoted around the world today; however, in light of experience their effectiveness needs to be evaluated. Accordingly, this chapter is not so much about the leaky building crisis per se or even about building regulation generally, but rather it is in effect about creating resilient and effective regulatory regimes.

This chapter is structured around three themes: why do regulatory regimes fail in general? Why did New Zealand's performance-based regulatory control regime fail? And what can we learn from this failure to create more resilient regimes in the future? The main message from this presentation is that some novel regulatory regimes can be quite experimental in nature. As experiments, they should be carefully monitored, with a particular focus first on what they are expected to deliver to society, and second, on the risks to delivery that arise out of the specific vulnerabilities of particular regulatory approaches. All regulatory approaches are different; they have their strengths and weaknesses. We need to know what they are and we need to be aware of their vulnerabilities.

\section{Why do Regulatory Policies Fail?}

At the outset, we should clarify what is meant by regulatory success and regulatory failure. I take a pragmatic approach: regulatory regimes are deemed to fail when the promises that were initially made when the regime was put in place are not met and, as a consequence, Parliament decides there are sufficient grounds to replace the existing regime with a new one. 
By taking this approach, I am making a distinction between regulatory failure and regulatory improvement. Regulatory failure is a systemic failure of the regulatory regime. Regulatory improvement results from ideas and analysis that point to a better way, but it is not precipitated by a complete loss of confidence in the existing regime.

Much has been written on the sources of regulatory failure-including John Braithwaite's list produced for the OECD on why businesses do not comply with the law (Improving Regulatory Compliance, 1993). Braithwaite identified the following sources of non-compliance: failure of business to understand the law; a lack of commitment by business to the objectives that lie behind the law or the rules chosen to secure these objectives (or both); a perception by business that regulatory procedures are unjust; high cost of regulation; and enforcement including failure of deterrents, incapacitation and persuasion.

Of course, non-compliance with the law by itself does not inevitably result in regulatory failure. It is a matter of degree. For example, if some businesses fail to understand the law, this suggests the need for a more effective educational or enforcement strategy. If, however, most businesses do not know what they must do to meet their obligations under the law, not only will the law fail to achieve its objectives, but also the whole regulatory approach is called into question.

\section{Why did this Particular Regulatory Policy Fail?}

Parliament adopted a new law in 1991 that introduced a novel approach to the regulation of buildings. It was in part a reaction to what was described as a building industry that was over-regulated and controlled, and in part a response to the newly popular idea that regulatory requirements should be couched in terms of aims and performance rather than prescription and detailed rules.

Prior to 1991 the regulatory regime governing buildings in New Zealand was highly prescriptive. If you were a builder you would have to go and get the manual off the shelf, or perhaps you wouldn't even need to, because you would have been trained in a particular conservative style of building in New Zealand. It was a traditional industry with traditional designs and materials, which were reflected in numerous and complex local government by-laws. When the 1991 Act was created, it replaced somewhere between 300 and 400 local government by-laws with a single performance statute and performance-based building code. So the regime went from highly prescriptive to highly performance-based.

The idea of performance-based regulation was promoted as a general response to the high cost and inflexible nature of prescriptive regulation. In the 1980s and 1990s these approaches were pervasive and adopted not just in the building 
area, but also in the regulation of occupational safety and health, environmental planning, hazardous substances, and electricity and gas safety. Here, I cannot describe in detail how performance-based regulatory regimes are structured in all their many manifestations because all of the regimes in New Zealand are a little bit different, but suffice to say they all share one characteristic: the requirements that regulated entities must meet (and for that matter that regulators must enforce) are couched as high-level goals.

I can best illustrate this with reference to the requirement in the New Zealand Building Code relating to water ingress. The code requirement is that buildings must be constructed to provide adequate resistance to penetration by, and accumulation of, moisture from the outside. Prior to 1991, homeowners and the building industry together with government regulators did not need to worry about what was adequate. They could rely on prescriptive building standards often based on traditional construction methods, which in turn were embedded in the training of designers and builders. After 1991 prescriptive standards could still be used to inform practice but now they became what was known as 'acceptable solutions'. Designers and builders, however, now had a choice: they could seek approval for new designs and construction methods known as alternative solutions. The approval bodies - the territorial authorities - were required to decide whether these design and construction methods met the Building Code requirements for adequacy based on reasonable grounds.

From the mid 1990s, territorial authorities approved building designs that involved monolithic cladding, a construction method that didn't require a cavity between the cladding and the wall. In addition, joints were secured using sealants. Kiln-dried timber, itself an innovation, was typically used rather than traditional treated timber framing, and building designs did not include eaves. This was a response to market demands for larger houses on smaller sections or blocks, as it allowed houses to be built closer to boundary lines. This combination of modern design features and building technologies ultimately failed. The absence of eaves meant that more rain soaked the cladding. The cladding system did not provide adequate resistance to penetration by moisture from the outside. Water that penetrated the cladding accumulated because there was no cavity to allow it to drain away or dry out. The kiln-dried timber framing rotted when the moisture content reached and stayed at a certain level.

In total, since 1991, at least 42000 buildings have been affected, and the consensus view is that the costs are in excess of NZ\$11 billion. The real cost is eventually likely to be even higher than that. All of those who had a role to play in the building-control regime failed to predict how this particular combination of building technologies would perform in practice. The extent to which the cladding system would keep out New Zealand's wind-driven rain, the susceptibility of kiln-dried timber to rotting, the very high standard of 
workmanship required, and the need for ongoing maintenance were not taken into account in decisions to purchase, design, approve, build and maintain houses. What was deemed adequate by regulators when this combination of designs and building technologies was approved later proved to be demonstrably inadequate in practice. So, was this a case of intentional non-compliance with the requirements of the Building Code? While on the margin there were no doubt examples of poor workmanship, on the whole there was no intention to defeat the purpose of the law. This was an example of involuntary non-compliance.

\section{Performance-Based Regulation and Regulatory Failure}

I wish now to explore the role performance-based regulation played in this housing crisis, and associate it with the sources of regulatory failure. The New Zealand Building Code is performance-based. It sets goals but does not prescribe what must be done to achieve those goals. In effect the prime legal requirement was clearly stated: buildings must provide adequate resistance to penetration by and the accumulation of moisture from the outside.

While the goal was clearly stated, the law nonetheless created uncertainty, as it required judgments to be made about what was adequate, and did not provide guidance on who was best placed to exercise this judgment or how this judgment should be exercised. This is a defining feature of performancebased regulatory regimes. They rely on judgment (and for the most part, expert judgment) in situations where there are no precedents and often commercial pressures. The level of expertise must be commensurate with the complexity of the decision that is being taken. The more complex the judgment, the higher is the skill level required.

Returning to Braithwaite's six reasons for business's non-compliance with the law, which at the extreme will result in regulatory failure, I can find two that are potentially relevant to the performance and possible failure of performance-based regulatory regimes. The first is a failure of business to understand the law. In performance-based regulatory regimes, this can be more sharply defined as a failure by regulated entities to understand what is required to meet high-level performance requirements in situations where there are no precedents. The second is enforcement failure, including the failure of deterrents, incapacitation and persuasion. In performance-based regulatory regimes I would describe this as a failure by enforcement agencies to evaluate the efficacy of new technologies against high-level performance requirements in situations where there are no precedents. 


\section{'This Must Never Happen Again': Creating resilient regulatory systems}

Since the crisis, we often hear it said that 'this must never happen again'. This is a mantra often repeated in the press and in royal commission reports. What can we learn from the failure of the building-control system to help us create more resilient regulatory regimes in the future? How do we resolve the problems of performance-based regulation, which might be described as dependence on expert judgment in complex decision-making contexts?

There are four possible solutions. One is to create more specific and measurable performance requirements. Colleagues in the building regulator division of the Ministry of Business, Innovation and Employment are taking this approach, and perhaps the term 'adequate' will not be as prevalent in the Building Code in the fullness of time.

A second solution is to ensure these problems do not arise by relying on safe precedents. This is the most conservative strategy. In the regulatory jargon it would involve reverting to prescriptive regulatory regimes. Research undertaken by the New Zealand Treasury indicates that some regulators are adopting this approach; effectively, our regulatory regimes and regulators are becoming much more conservative across the board; however, while prescription may provide certainty, it may also reduce flexibility, constrain innovation, impose excessive costs, and in some situations result in a level of regulatory complexity over time that either creates a disincentive to comply or focuses compliance on the wrong things. In other words, there is a risk-perhaps small, but a risk nonethelesswe could end up with the worst of both worlds. We may unintentionally produce high-cost regulatory regimes that do not achieve the state's primary objectives, be they related to health, safety, environmental protection or consumer and investor protection.

A third solution is to improve the quality of decision-making in situations where there are no precedents. We know some people or groups of people are better able to predict how novel technologies such as new building systems and products will perform in practice. They are described as experts and we rely on their professional judgment. Again, research undertaken within the New Zealand Treasury indicates that some regulators are adopting this approach, and in fact some regulatory regimes - traditional ones - have always been based on this approach. Relying on experts is, however, not as foolproof as it might first appear. What constitutes an expert has been studied at some length, and in some contexts, such as predicting the performance of complex and unproven technologies, a particular quality of expert is required. If we create regulatory regimes that are reliant on experts, we must be confident that experts are in fact available. 
A fourth, more innovative solution is to treat novel technologies as experiments. From the outset, we must accept that we do not know how novel technologies will perform in all circumstances of their use. If we had treated a few monolithic clad buildings as site experiments, we would have been able to discover early on that they had deficiencies and might fail in certain circumstances. We could have monitored how they actually performed in the field, and against the inclement weather, and in the course of doing so we might have detected a problem in a timely manner. A few hundred vulnerable buildings could have been built before the serious problems were identified, and we could have avoided the tens of thousands of defective buildings that were ultimately built.

All of these are each plausible strategies. They might be employed either individually or in combination to resolve what we now know about the inherent weaknesses of performance-based regulation, but each of these strategies is itself subject to some uncertainty. How will they work in practice?

\section{The Importance of Monitoring and Best Practice}

This takes me to my final point: we must not assume a 'set and forget' approach to the design and implementation of regulatory regimes. At one level we must treat regulatory regimes as experiments, and indeed novel regimes such as the 1991 Performance-Based Building Control Regime was highly experimental. As experiments, regulatory regimes must be monitored and evaluated, and corrective action should be taken if required. The risk of not monitoring and evaluating is that we are surprised when regulatory regimes do not perform as expected and occasionally fail. More importantly, the consequences of failure can range from unpleasant to catastrophic, as we have found in the building area.

Avoiding failures completely is the ultimate objective, but minimising the risk and impact is also an important goal. If we accept the importance of monitoring and evaluating, the question becomes: what do we actually monitor? Health, safety and environmental outcomes, or indeed building quality outcomes, are important indicators of the performance of regimes. They tend to be after the event.

We also require measures of the health of regulatory regimes that allow us to make an assessment along the way. The New Zealand Treasury has developed a set of best regulatory practice principles and performance indicators, and assessed some 60 regulatory regimes against these. ${ }^{1}$ The Treasury view is that

1 The full best-practice regulatory principles paper can be found at: <http://www.treasury.govt.nz/ economy/regulation/bestpractice $>$. 
regular monitoring against these principles, having regard to the indicators, is one important way of tracking the performance of regulatory regimes and identifying areas of risk that might require further review. The principles and indicators can also act as targets for continuous improvement and design criteria for new regimes.

The best-practice regulatory principles are

- growth-supporting - economic objectives are given an appropriate weighting relative to other specified objectives

- proportional-the burden of rules and their enforcement should be proportional to the benefits that are expected to result

- flexible - regulated entities should have scope to adopt least-cost and innovative approaches to meeting legal requirements

- durable - the regulatory system has the capacity to evolve to respond to changing circumstances

- certain and predictable - regulated entities have certainty as to their legal obligations, and the regulatory regime provides predictability over time

- transparent and accountable-rules development, implementation and enforcement should be transparent

- capable regulators - the regulator has the people and systems to operate an efficient and effective regulatory regime.

Each of the principles is associated with a set of performance indicators.

My ex-post assessment of the 1991 Building Control Regime indicated that it failed against a number of these principles and performance indicators. Hindsight of course is a wonderful thing, but our judgment is that if the assessment had been made in the 1990s, it would have revealed some latent weaknesses in the regime. We would have discovered major misgivings in relation to proportionality. We would have uncovered evidence of poor durability. And, third, we would have questioned the capability of the regulators to exercise expert judgments on novel building technologies. Would such an assessment have reduced the risk of building failures? Probably, but we will never know because the assessment was never done.

\section{Reference}

Mumford, P. 2011. Enhancing Performance-Based Regulation: Lessons from New Zealand's Building Control System (Wellington: Institute of Policy Studies). 
This text taken from Future-Proofing the State: Managing Risks, Responding to Crises and Building Resilience, edited by Jonathan Boston, John Wanna, Vic Lipski and Justin Pritchard, published May 2014 by ANU Press, The Australian National University, Canberra, Australia. 